\section{P17 (continued)}

experiences. Faculty include resident and nonresident professors. Most courses have 20-25 students. A part-time faculty director and a portion of a full-time administrator manage the program, which enrolls approximately $60 \mathrm{ma}-$ triculated students.

Evaluation: Current and former students completed a 23-item online evaluation $(n=45)$. Most learned about the program through online searching. Almost all agreed the OL-MPHN meets learning and professional development needs. Cited OL-MPHN strengths were its convenience and flexibility, applicable content, knowledgeable and accessible instructors, and peer interaction. Weaknesses identified were group work, challenging course load, cost, and lack of face-to-face interaction. Reported "useful" or "very useful" were asynchronous discussions, synchronous webinars, and collaborative projects. Satisfaction with student-faculty and student-student interaction was high.

Conclusions and Implications: OL-MPHN participants reported, although the program takes effort, they were highly satisfied and would recommend the program to others.

Funding: None.

\section{P18 Improving Eating and Physical Activity Behaviors for Middle School Students: Coupling Empowerment and Education}

Mary Anne Burkman, MPH, RD, BurkmanM@

dairycouncilofca.org, Dairy Council of California, 1101

National Drive, Suite B, Sacramento, CA 95834

Objective: To demonstrate the effectiveness for increased behavior change by implementing two complementary programs. One is a student-led advocacy program focused on improving eating and physical activity behaviors; the other, a comprehensive nutrition education curriculum for middle school.

Target audience: Middle school students.

Theory, Prior Research, Rationale: Dairy Council of California distributes a middle school nutrition education program called Exercise Your Options, validated through formal evaluations. National Dairy Council, in collaboration with the National Football League and USDA, provides a student-led program, Fuel Up to Play (FUTP) 60, that empowers students to make small, positive changes at home and school. Given the shared objectives and target audience of these two programs, it was thought that implementing both programs together could increase the combined impact.

Description: Alignments between the two programs were developed to facilitate implementation at the school level. Students learn how to apply healthy eating and physical activity knowledge obtained through the classroom lessons in typical real-world situations, such as purchasing lunch in a mall food court. By coordinating the FUTP 60 activities with the Exercise Your Options lessons, students are more engaged and able to make changes at the school and individual levels.
Evaluation: Evaluation results documenting the impact of this integrated approach will be shared.

Conclusions and Implications: Behavior change with regards to healthy eating and physical activity can be strengthened when coordinated with an empowerment program. By implementing FUTP 60 alongside Exercise Your Options, students are better equipped to make balanced food choices and increase physical activity for the long-term.

Funding: Dairy Council of California.

\section{P19 Lessons Learned from Planning and Implementing Sodium Reduction Strategies with Independent Restaurants}

Karen Strazza, MPH, kstrazza@rti.org, RTI International, 3040 East Conrwallis Road, PO Box 12194, Research Triangle Park, NC 27709-2194; H. Kane, PhD; A. S. Anater, PhD, MPH, MA; C. Frost, BA; M. Margolis, BA; J. Hersey, PhD, MA, MS

Objective: To share lessons learned from public health partnerships with independent restaurants in sodium reduction efforts.

Target audience: Public health departments, Independent restaurant owners.

Theory, Prior Research, Rationale: Restaurants are an important venue for population-based sodium reduction strategies as they generally have more sodium per calorie compared with foods from stores, have avenues for influencing procurement and meal preparation, and present opportunities to build relationships with nontraditional public health partners.

Description: In 2010, CDC launched the Sodium Reduction in Communities Program to reduce sodium intake by implementing community-based approaches. Health departments in 3 diverse US communities collaborated with independent restaurants to implement sodium reduction approaches in independent restaurants.

Evaluation: Evaluators conducted semi-structured, qualitative interviews with program staff and partners and conducted a cross-site thematic analysis. These interviews explored the implementation process and lessons learned. Respondents identified several lessons learned from working with independent restaurants to reduce sodium. These include: 1) involving individuals with restaurant and food industry expertise; 2) finding cost effective ways to reduce sodium content; 3 ) making gradual reductions in the sodium content of menu items; 4) labeling lower sodium items in positive terms (e.g., "heart healthy," "sodium friendly").

Conclusions and Implications: Although working with independent restaurants to implement sodium reduction efforts is a new and challenging endeavor, restaurants do offer the potential to affect the sodium intake of a large segment of the U.S. population. Reducing the sodium consumed by restaurant-goers can also help to increase demand for lower sodium products on the part of suppliers.

Funding: Centers for Disease Control and Prevention. 